\title{
Redaksioneel
}

\section{Hervormde Teologiese Studies Ortografiese vereistes}

Alle artikels, boek- en proefskrifbesprekings se ortografiese inrigting en literatuurverwysings moet voldoen aan die vereistes soos hieronder gepubliseer. Artikels kan geskryf wees in Afrikaans, Engels, Duits of Frans. Artikels moet aan die begin voorsien wees van ' $n$ taalversorgde Engelse ekserp wat naas ' $n$ vertaling van die titel, 'n kort uiteensetting (hoogstens eenhonderd woorde) van die bedoeling van die artikel bevat. Medewerkers se aandag word gevestig op die reëling dat bydraes formeel en inhoudelik deur die redakteur en ander vakkundiges gekeur word.

\section{TIK VAN MANUSKRIP EN ADMINISTRASIE}

Die manuskrip moet getik word in een en 'n half spasiëring op A4-grootte papier. Twee rekenaaruitdrukke, tesame met disket op Nota Bene, Xi-Write of ASCII-kode ingesleutel, moet by voorlegging van bydrae met die oog op oorweging vir publikasie by adres HTS, Posbus 5777, Pretoria 0001, ingedien word.

\section{OPSKRIFIE}

Alleen die eerste vlak opskrif word in hoofletters getik. Nommer al die opskrifte volgens die desimale nommerstelsel. Alle opskrifte word vet (bold) gedruk. Vermy die nommering van paragrawe wat nie opskrifte het nie en let op die puntering:

\section{EERSTE VLAK OPSKRIF}

1.1 Tweede vlak opskrif

\subsubsection{Derde vlak opskrif}

\subsubsection{Vierde vlak opskrif}

Gebruik daarna (a) en (i).

Maak seker dat alle genommerde paragrawe opskrifte het.

\footnotetext{
- Die ortografiese vereistes is opgestel aan dic hand van Kilian, J 1989. Form and style in theological terts: A guide for the use of the Hanvard Reference system. 2nd rev ed. Pretoria: University of South Africa. Form and style is 'n publikasic van die Instituut vir Teologiese Navorsing, UNISA. Erkenning word hiermee aan die Instituut verleen.
} 


\subsection{Items in 'n lys}

Items hoef nie noodwendig genommer te word nie. Hulle kan aangedui word deur 'n aandagstreep (-) of asterisk (*).

\section{SPELIING OF SKRYFWYSE}

Volg die spelling van die Handwoordeboek van die Afrikaanse Taal (HAT). Dit geld ook vir die gebruik van hoofletters.

\section{TRANSLITERASIE}

Grieks, Hebreeus, Aramees ensovoorts word of ingesleutel df baie duidelik met die hand geskryf sodat dit deur die kantoor van die redakteur ingesleutel kan word.

\section{KURSIVERING}

Kursiveer woorde in antieke en vreemde tale. Verder word titels van boeke, versamelwerke, tydskrifte en koerante gekursiveer. Titels van Bybelboeke, Bybelvertalings, apokriewe en pseudepigrawe word nie gekursiveer nie.

Woorde in vreemde tale wat in Afrikaans so gereeld gebruik word dat hulle byna 'ver-Afrikaans' het, soos ad hoc, et al, sic, word nie gekursiveer nie. Beklemtoning word gekursiveer. Toon met kantaantekening, indien nodig, waar onderstreping kursivering veronderstel.

\section{AFKORTINGS}

Erkende afkortings moet alleen in hakies, notas en literatuurverwysingslys gebruik word. Punte word by afkortings weggelaat en 'n spasie word vir 'n punt gelaat.

\subsection{Afkortings vir Bybelboeke (laat punktuasie weg)}

6.1.1 Afrikaans (soos deur die SA Akademie vir Weienskap en Kuns aanbeveel)

$\begin{array}{lllllll}\text { Gen } & \text { Eks } & \text { Lev } & \text { Num } & \text { Deut } & \text { Jos } & \text { Rig } \\ \text { Rut } & 1 \text { Sam } & \text { 2 Sam } & 1 \text { Kon } & 2 \text { Kon } & 1 \text { Kron } & 2 \text { Kron } \\ \text { Esra } & \text { Neh } & \text { Est } & \text { Job } & \text { Ps } & \text { Spr } & \text { Pred } \\ \text { Hoogl } & \text { Jes } & \text { Jer } & \text { Klaagl } & \text { Eseg } & \text { Dan } & \text { Hos } \\ \text { Joël } & \text { Am } & \text { Ob } & \text { Jona } & \text { Miga } & \text { Nah } & \text { Hab } \\ \text { Sef } & \text { Hag } & \text { Sag } & \text { Mal } & & & \\ & & & & & & \\ \text { Matt } & \text { Mark } & \text { Luk } & \text { Joh } & \text { Hand } & \text { Rom } & \text { 1 Kor } \\ \text { 2 Kor } & \text { Gal } & \text { Ef } & \text { Fil } & \text { Kol } & \text { 1 Tess } & \text { 2 Tess }\end{array}$




$\begin{array}{lllllll}1 \text { Tim } & 2 \text { Tim } & \text { Tit } & \text { Filem } & \text { Heb } & \text { Jak } & 1 \text { Pet } \\ 2 \text { Pet } & 1 \text { Joh } & 2 \text { Joh } & \text { 3 Joh } & \text { Jud } & \text { Op } & \end{array}$

6.1. Engels (soos deur die NTWSA aanbeveel)

$\begin{array}{lllllll}\text { Gn } & \text { Ex } & \text { Lv } & \text { Nm } & \text { Dt } & \text { Jos } & \text { Jdg } \\ \text { Rt } & 1 \mathrm{Sm} & 2 \mathrm{Sm} & 1 \mathrm{Ki} & 2 \mathrm{Ki} & 1 \mathrm{Chr} & 2 \mathrm{Chr} \\ \text { Ezr } & \mathrm{Neh} & \mathrm{Es} & \mathrm{Job} & \mathrm{Ps} & \mathrm{Pr} & \mathrm{Ec} \\ \mathrm{Can} & \mathrm{Is} & \mathrm{Jr} & \mathrm{Lm} & \mathrm{Ezk} & \mathrm{Dn} & \mathrm{Hs} \\ \mathrm{Jl} & \mathrm{Am} & \mathrm{Ob} & \mathrm{Jnh} & \mathrm{Mi} & \mathrm{Nah} & \mathrm{Hab} \\ \mathrm{Zph} & \mathrm{Hg} & \mathrm{Zch} & \mathrm{Ml} & & & \\ & & & & & & \\ \mathrm{Mt} & \mathrm{Mk} & \mathrm{Lk} & \mathrm{Jn} & \mathrm{Ac} & \mathrm{Rm} & 1 \mathrm{Cor} \\ 2 \mathrm{Cor} & \mathrm{Gl} & \mathrm{Eph} & \mathrm{Phlp} & \mathrm{Col} & 1 \mathrm{Th} & 2 \mathrm{Th} \\ 1 \mathrm{Tm} & 2 \mathrm{Tm} & \mathrm{Tt} & \mathrm{Phlm} & \mathrm{Heb} & \mathrm{Ja} & 1 \mathrm{Pt} \\ 2 \mathrm{Pt} & 1 \mathrm{Jn} & 2 \mathrm{Jn} & 3 \mathrm{Jn} & \mathrm{Jude} & \mathrm{Rv} & \end{array}$

\title{
6.2 Skryfwyse vir teksgedeeltes (slegs in hakies)
}

\author{
Matt 12:39 \\ Matt 12:39-44 \\ Matt 12:39, 46, 50; 13:10-15 \\ Matt 12, 13, 14
}

Vermy die gebruik van ' $v$ ' en 'vv' of 'ev' (Engels: 'f' of 'ff). Gee die omvattende Bybelverse of bladsynommers.

\subsection{Ander afkortings}

Vir 'n lys van afkortings vir klassieke, apokriewe, pseudepigrawe, Dooie See Rolle en Nag Hammadi-literatuur ensovoorts, raadpleeg Kilian, J 1989. Form and style in theological texts: A guide for users of the Harvard reference system. 2nd rev ed. Pretoria: University of South Africa.

Standaardafkortings vir teologiese tydskrifte en teologiese naslaanwerke kan gevind word in Schwertner, S 1974. Internationales Abkürzungsverzeichnis für Theologie und Grenzgehiete. Berlin: De Gruyter (kyk ook Addendum agteraan). Indien afkortings nie in Schwertner of sy Addendum gevind word nie, moet titels voluit geskryf word. Die Nuwe Afrikaanse Bybelvertaling word afgekort (in Afrikaans en Engels) met NAB. 


\section{AANHALINGS}

Aanhalings moet presies met die oorspronklike ooreenkom. Indien getwyfel word oor die korrektheid van die oorspronklike aanhaling, mag 'sic' in 'n vierkante hakie direk na die woord of woorde wat die outeur meen korrek is, geplaas word. Aanhalings word in enkele aanhalingstekens geplaas, terwyl aanhalings binne 'n aanhaling in dubbele aanhalingstekens geplaas word.

Aanhalings van meer as vyf getikte reëls moet vyf spasies van die linker- en regterkantlyn geblok (indent) word. Sulke aanhalings word nie in aanhalingstekens geplaas nie.

Woorde, sinne of frases wat by aanhalings uitgelaat word, moet aangedui word deur drie punte, sonder spasie tussen die woord en punt, te gebruik. Vier punte word aan die einde van 'n sin gegee. Gebruik hoofletter in vierkante hakies na vier punte wanneer daar na weglating gevolg word met middeldeel van 'n volgende sin, byvoorbeeld: 'Teologie gaan om 'n "predik-ontwerp", ....[I]n die lig hiervan kan teologie nooit 'n teorie vir praxis wees nie....'

\section{LITERATUURVER WYSINGS}

Die Harvardverwysingstegniek word in die Hervormde Teologiese Studies gebruik. Hierdie stelsel word ook die outeur-datumverwysingstegniek genoem, aangesien slegs die outeur(s) en datum van publikasie in die teks in hakies gegee word. Indien daar na 'n spesifieke bladsy verwys word, word die bladsynommer(s) bygevoeg: (Scholl 1976:55).

Die volledige bibliografiese gegewens van die werke wat geraadpleeg is, word in 'n lys aan die einde van die artikel onder die opskrif Literatuurverwysings (let op kleinletters en vetdruk) gegee. Omdat die lys die sleutel is tot die verwysings in die teks sowel as tot bronne-ontsluiting in die biblioteek, word die outeur se van (in kleinletters - let op: voorheen was dit hoofletters; kyk voorbeelde hieronder) en voorletters eerste gegee. Daarna volg die datum. Die lys word alfabeties gerangskik. Indien daar meer as een werk van dieselfde outeur is, word die werke chronologies gerangskik. Dieselfue outeursnaam word nie in die literatuurverwysingslys herhaal nie, maar met 'n aandagstreep aangedui.

Alhoewel verwysings na boeke en tydskrifartikels nie in die literatuurverwysingslys geskei word nie, word boeke en tydskrifartikels om praktiese redes hier apart behandel. 


\subsection{Boeke}

Inligting in verband met boeke word in die volgende volgorde gegee:

Outeur, VOORLETTERS datum. Titel. Uitgawe. Plek van uitgawe: Uitgewer. (Reeks.)

Let op die gebruik van leestekens, hoofletters, kleinletters, kursivering en spasies:

Barr, J 1969. Biblical words for time. 3rd ed. London: SCM. (SBT 33.)

Via, D O 1970. Die Gleichnisse Jesu: Ihre literarische und existentiale Dimension. München: Kaiser. (BEvTh 57.)

\section{Voorbeelde}

Vervolgens word voorbeelde gegee van verwysings in die teks (met 'n $\mathrm{T}$ aangedui). Daarna word aangedui hoe die verwysings in die literatuurverwysingslys aangegee word (met ' $\mathrm{L} \mathrm{L}$ aangedui).

Let op dat die outeur(s) of instansie wat in die plek van die outeur(s) aangegee word, nie in hoofletters aangegee word nie, maar in kleinletters. Geen spasie word tussen datum en bladsynommer(s) gelaat nie maar 'n spasie word wel gelaat tussen die plek van uitgawe en die uitgewer, sowel as tussen voorletters van outeursname en tussen hooftitel en subtitel.

\subsubsection{Een outeur}

T (Krentz 1965:55)

L Krentz, L 1965. The historico-critical method. Philadelphia: Fortress.

8.1.2 Dieselfde outeur maar verskillende werke

$T$ (Matera 1987:233)

T (Matera 1988:3)

L Matera, F J 1987. The plot of Matthew's Gospel. CBQ 49, 233-253.

L --- 1988. The prologue as the interpretative key to Mark's Gospel. JSNT 34, 3-20.

8.1.3 Een outeur met meer as een werk in dieselfde jaar

$T$ (Schmithals 1980a:76)

T (Schmithals 1980b:126)

L Schmithals, W 1980a. Die theologische Anthropologie des Paulus. Stuttgart: 
Kohlhammer. (Kohlhammer Taschenbücher 1021.)

L -.. 1980b. Das Evangelium nach Lukas. Zürich: Evangelischer Verlag. (SBK NT 3.1.)

8.1.4 Twee outeurs (let op ' $\&$ ' in plaas van die voorsetsel 'en' asook op spasie tussen voorletters)

T (Welbourn \& Argot 1966:123)

L Welbourn, F B \& Agot, B A 1966. A place to feel at home. London: Oxford University Press.

8.1.5 Twee outeurs met dieselfde van

T (Aland \& Aland 1982:17)

T Die Alands (1982:17) onderskei....

L Aland, K \& Aland, B 1982. Der Text des Neuen Testaments. Stuttgart: Deutsche Bibelgesellschaft.

8.1.6 Drie outeurs (let op punktuasie binne hakie by reeksaanduiding en dat geen spasie gelaat word tussen '5.' en 'Aufl' nie; vgl egter '2nd ed.')

T Eerste verwysing (Adam, Kaiser \& Kümmel 1975:180)

$T$ Volgende verwysings (Adam et al 1975:183)

T Adam en andere (1975:183) beweer dat....

L Adam, G, Kaiser, O \& Kümmel, W G 1975. Einführung in die exegetischen Methoden. 5.Aufl. München: Kaiser. (Studium Theologie 1.)

8.1.7 Vier of meer outeurs (let op dat 'et al' nie gekursiveer word nie)

T Eerste en volgende verwysings (Pelikan et al 1964:96)

T Pelikan en andere (1964:96) spreek hulle....

L Pelikan, J, et al 1964. Religion and the university. University of Toronto Press.

\subsubsection{Redaksionele werk}

T (Bettenson 1967:85)

L Bettenson, H (ed) 1943. Documents of the Christian church. London: Oxford University Press.

Gewoonlik word daar nie na 'n saamgestelde werk in die algemeen verwys nie, maar eerder na die besondere bydrae in so 'n werk (kyk 8.1.9). 
Afkortings vir redakteur of samesteller word in die taal van die boek gegee: (ed), (eds), (éd), (Hrsg), (red) (reds), (comp), (comps), (samest), (samests).

8.1.9 Bydrae in redaksionele werk (let op bladsynommers wat aangedui word vó́r die vermelding van plek van uitgawe)

$T$ (Baumgärtel 1963:135)

L Baumgärtel, F 1963. The hermeneutical problem of the Old Testament, in Westermann, C (ed), Essays on Old Testament hermeneutics, 135-159. Richmond: John Knox.

8.1.10 Meer as een bydrae uit dieselfde redaksionele werk

T (Cooper 1983:14)

T (Cross 1983:119)

T (Halpern 1983:44)

L Cooper, A M 1983. The life and times of King David according to the book of Psalms, in Friedman 1983:117-131.

L Cross, F M 1983. The epic traditions of early Israel: Epic narrative and the reconstruction of early Israelite institutions, in Friedman 1983:13-39.

L Friedman, R E (ed) 1983. The poet and the historian: Essays in literary and historical Biblical criticism. Chico: Scholars Press.

L Halpern, B 1983. Doctrine by misadventure: Between the Israelite source and the biblical historian, in Friedman 1983:41-73. .

8.1.11 Saamgestelde werk van bekende outeur

T (Knox 1848:76)

L Knox, J 1848. The works of John Knox, ed by J Lang. Edinburgh: Clark.

8.1.12 Korporatiewe liggaam as outeur

T Eerste verwysing (Nederduitsch Hervormde Kerk 1945 = NHKA 1945)

$T$ Volgende verwysing (NHKA 1945)

L Nederduitsch Hervormde Kerk van Afrika. Algemene Kerkvergadering 1945. Notule van die Algemene Kerkvergadering 1945. Argief van die Nederduitsch Hervormde Kerk, Pretoria.

T Eerste verwysing (Nederduitse Gereformeerde Kerk $1977=$ NGK 1977)

T Volgende verwysings (NGK 1977)

L Nederduitse Gereformeerde Kerk. Algemene Sinode 1977. Ras, volk en nasie en volkereverhoudinge in die lig van die Skrif. Kaapstad: NG Kerkuitgewers. 


\subsubsection{Titel as outeur}

Indien daar op die titelblad geen aanduiding is van 'n persoon of liggaam wat aanspreeklikheid aanvaar vir 'n boek nie, word die titel van die boek in plek van die outeur gebruik:

T Eerste verwysing (What Bible can you trust? 1974:18)

T Volgende verwysings (What Bible 1974:19)

L What Bible can you trust? 1974. Nashville: Broadman.

8.1.14 Bydrae in woordeboek of ensiklopedie (let op 's v' = 'sub verbo' = 'onder die naam')

- Outeur bekend

T (Hesse 1973)

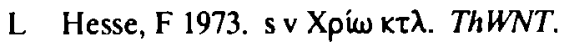

* Outeur onbekend

T (Bibel-Lexikon 1956)

L Bibel-Lexikon 1956. s v Cäsarea.

- Plek van uitgawe en uitgewer word in die geval van woordeboeke en ensiklopedieë nie vermeld nie.

8.1.15 Skripsies, verhandelings en proefskrifte (let op dat kursivering nie voorkom nie)

T (Pienaar 1989:6)

L Pienaar, P J H S 1989. Die sondaars in die tyd van Jesus en Paulus. BDskripsie, Universiteit van Pretoria.

T (Van Staden 1988:92)

L Van Staden, P J 1988. Die struktuur van die Eerste Johannesbrief. DDproefskrif, Universiteit van Pretoria.

8.1.16 Werke bestaande uit meer as een volume

- Elke volume dieselfde titel

T (Tillich 1951:217)

L Tillich, P 1951. Systematic theology, vol 1. Chicago: University of Chicago Press.

- Elke volume 'n ander titel

T (Charlesworth 1983:321)

L Charlesworth, J H (ed) 1983. The Old Testament Pseudepigrapha. Vol 1, Apocalyptic literature and testaments. New York: Doubleday. 


\subsubsection{Feesbundels}

T (Coats 1981:33)

L Coats, G W 1981. The curse in God's blessing: $G n$ 12, 1-4a in the structure and theology of the Yahwist, in Jeremias J \& Perlitt, L (Hrsg), Die Botschaft und the Boten: Festschrift für Hans Walter Wolff zum 70. Geburtstag. Neukirchen: Neukirchener Verlag.

\subsubsection{Titels}

Skryf titels presies soos hulle op die titelblad verskyn, behalwe vir hoofletters en leestekens. Gebruik hoofletters alleen vir eiename, byvoeglike naamwoorde en eiename afgelei van selfstandige naamwoorde wat op eiename betrekking het, byvoorbeeld 'Kerk' verwysend na die Nederduitsch Hervormde Kerk van Afrika in die besonder.

Die newetitel begin met 'n hoofletter en word van die titel geskei deur 'n dubbelpunt.

\subsubsection{Plek en naam van uitgewer}

Slegs die eerste plek van uitgawe word vermeld. Vermy woorde by die naam van die uitgewer wat nie nodig vir identifikasie is nie, soos: 'co', 'Lid', 'press' en 'Verlag'. Die plek van uitgewer word in die taal van die boek gegee.

Behou egter 'press' en 'Verlag' na byvoeglike naamwoorde, byvoorbeeld: Neukirchener Verlag, Scholars Press.

Skryf universiteitsuitgewers altyd voluit, byvoorbeeld: University of Chicago Press, University of Toronto Press.

\subsubsection{Uitgawe}

Die uitgawe van die boek, tensy dit die eerste is, moet aangedui word. Onderskei tussen enersyds 'reprinting' en 'new impression', wat geïgnoreer kan word en andersyds 'edition' wat vermeld moet word. Die uitgawe word afgekort en in die taal van die boek gegee. Gebruik syfers, indien moontlik: 2 nd ed, $2^{e}$ éd, Fascim ed, 2.Aufl, 3de uitg, Hers uitg, Rev ed, 5de dr.

\subsection{Tydskrifte}

Inligting in verband met 'n tydskrif word soos volg gegee: Outeur, VOORLETTERS datum. Titel van artikel. Titel van tydskrif volumenommer, bladsye (voliedig).

Die tydskriftitel word afgekort volgens Schwertner, S 1974. Internationales Abkürzungsverzeichnis für Theologie und Grenzgebiete. Berlin: De Gruyter. 
Indien die afkorting nie in bogenoemde bron of sy Addendum agteraan voorkom nie, skryf die naam van die tydskrif uit.

L Geyser, P A 1985. Die relasionele waarheidsbegrip en die Christelike lewe: Die sinodale rapport van die GKN. HTS 41, 119-129.

Die volgnommer word in Arabiese syfers aangegee sonder die afkorting ' $v$ ', 'vol' of 'jrg' voorafgaande. Bladsynommers word volledig gegee. Indien datum van uitgawe of plek van uitgawe ontbreek, word in die plek van die verwysing na die datum die afkorting 's a' en na die plek van uitgawe die afkorting 's l' gebruik. As die datum van die uitgawe wel aan die gebruiker bekend is, hoewel dit nie in die boek of tydskrif eksplisiet vermeld is nie, word die datum in 'n vierkante hakie geplaas. Omdat die Henomide Teologiese Studies vanaf Jaargang 40 eksplisiet as 1984 gedateer is, kan die datums van vorige jaargange bereken word, byvoorbeeld:

T (Pont [1978]:92)

L Pont, A D [1978]. Die herderlijke brief van die sinode van 1837. HTS $34 / 4,91-105$.

Indien elke aflewering van 'n bepaalde tydskrif by bladsy een begin, moet die afleweringsnommer vermeld word. Die afleweringsnommer word geskei van die volumenommer deur 'n skuins streep (bv HTS 34/4, 91-105). Let daarop dat die bladsye van die Hervormde Teologiese Studies vanaf Jaargang 41 deurlopend per jaargang genommer word en word die volumenommers sedert Jaargang 41 nie meer aangedui nie.

8.3 Kerkblaaie en populêre tydskrifte (let op voorsetsel 'en' by vermelding van bladsynommers en afkorting bl, p)

T (Die Hervormer 1985:4)

T (Die Kerkbode 1985:16)

L Die Henormer Maart 1985. Gesonder grondslag vir tussenkerklike gesprek, bl 1 en 4.

L Die Kerkbode 27 Feb 1985. Verklaring oor 99-jaarhuurpag verwelkom, bl 1.

L Van Rensburg, F 1985. Openbare gebed, Die Kerkblad 10 April 1985, bl 16 en 17. 


\subsection{Koerante}

T (Die Transvaler, bl 1)

L Die Transvaler 16 April 1985. Susterkerke verskil oor afskaf, bl 1.

\section{VOETNOTAS EN ENDNOTAS}

Wanneer die Harvard-verwysingstegniek gebruik word, moet die gebruik van voetnotas vermy word. Miskien kan die inligting wat in 'n voetnota opgeneem wou word, in die teks self verwerk word. Indien dit onmoontlik is, moet dit uiters spaarsaam onderaan die betrokke bladsy geplaas word, aangewys met 'n asterisk. In buitengewone gevalle kan daar van endnotas deur middel van deurlopende nommering gebruik gemaak word (kyk HTS 45, 741-766). 